\title{
Menopause what to know
}

\begin{abstract}
There is a substantial amount of health information available on the Internet. The purpose of this research is to assess the quality of Internet based consumer health information specific to menopause. Accessing health information is a matter of vital importance to consumers. Women use the Internet to search for information regarding menopause symptoms, potential treatments, related diseases, and data on the reliability of information. However, quality of Internet information provided by consumers is a matter for enquiry. While the Internet is a primary source to gather health information, it is important that the information should not only be factual but also help individuals to distinguish reliable information from unreliable information presented by various websites. This study examines whether the information that menopausal woman receiving from websites on the Internet is factual and accurate. This study examined fifty websites to assess quality of information from Internet. This study examined information about menopause from various authors and looks at the quality.
\end{abstract}

Volume 3 Issue 2 - 2016

\author{
Linda Moyer \\ East Stroudsburg University, USA
}

Correspondence: Linda Moyer, East Stroudsburg University, 47I Route 940 Pocono Lake PA 18347, USA, Tel 570 646-5886, Email linmoyer@gmail.com

Received: October 22, 2016 | Published: December 07, 2016

\section{Health issues associated with menopause}

Some of the health conditions that are associated with menopause are; depression, cancers, osteoporosis, and heart disease. ${ }^{1-4}$ Menopause is the end of a woman's menstrual cycle and fertility and it is a normal condition that all women experience as they age. It occurs when the ovaries are no longer producing estrogen and progesterone, two necessary hormones for a woman's reproductive cycle to function. Depression can occur when there is a drop in estrogen levels during peri-menopause and menopause..$^{5-7}$ Depression during menopause is treated in much as the same way that depression is when it strikes at any other time in a female's lifetime. Menopause itself is not associated with an increased risk of developing cancer, however, the rates of many cancers, including breast cancer does increase with age.

Osteoporosis is a disease that weakens the bones, increasing the risk of sudden and unexpected fractures. ${ }^{8}$ The disease often progresses without any symptoms or pain. This is called the silence disease. Generally, osteoporosis is not discovered until the weakened bones cause painful fractures, usually starting in the back or the hips. ${ }^{9-11}$ One you have an osteoporosis fracture you are at a high risk of having another. Many women think that heart disease is a man's disease. Heart disease is the number one killer of women. Once a woman reaches the age of 50, nearly half of all deaths in women are due to some form of cardiovascular disease. ${ }^{12}$ When a women reaches menopause she is usually about 50, the risk for heart disease increases. In young women who have undergone early or surgical menopause, who do not take estrogen, their risk for heart disease is also higher. A healthy lifestyle goes a long way in preventing heart disease, osteoporosis, cancer and depression. Eating more fruits and vegetables, less fats and getting plenty of exercise will decrease these types of diseases.

\section{Acknowledgements}

None.

\section{Conflict of interest}

The author declares no conflict of interest.

\section{References}

1. Alexander LL, LaRosea JH, Bader H, et al. New Dimensions in Women's Health. 5TH ed. UK: Jones and Bartlett publishers; 2010. p. 1-480.

2. Cardelle AJ, Rodriguez E. A quality of spanish health information websites: an emerging disparity. Journal of Prevention \& Intervention in the Community. 2005;29(1-2):85-102.

3. Edlin G, Golanty E. Health and Wellness. 8th ed. UK: Jones and Bartlett publishers; 2004.

4. Godin S, Truschel J. Quality assurance of self- help sites on the internet. Journal of Prevention \& Intervention in the Community. 2005;29(12):67-84.

5. Godin Steve. Quality Assurance Rating tool of Internet Based Consumer Health Education Version \#4; 2004.

6. Hefet M. The Gap Between Google and Rivals May Be Smaller Than You Think. The New York Times, USA; 2009.

7. Howe W. A Brief History of the Internet. USA; 2009.

8. Leung L. Internet embeddedness: Links with online health information seeking, Expectancy value/quality of health information websites, And internet usage patterns. Cyberpsychol Behav. 2007;11(5):565-569.

9. McKenzie JF, Pinger RR, Kotecki JE. An Introduction to Community Health. 5th ed. USA: Jones and Bartlett Publishers; 2005. p. 1-614.

10. Risk A, Dzenowagis J. Review of internet health informatio quality initiatives. J Med Internet Res. 2011;3(4):E28.

11. Sillence E, Briggs P, Harris PR, et al. How do patients evaluate and make up of online health information? Soc Sci Med. 2007;64(9):1853-1862.

12. Thom F, Camille R. Computer and Internet Use in the United States. U.S. Census Bureau, USA; 2013. p. 1-16. 